\title{
Selenium treatment in autoimmune thyroiditis: 9-month follow-up with variable doses
}

\author{
Omer Turker, Kamil Kumanlioglu ${ }^{1}$, Inanc Karapolat ${ }^{\mathbf{2}}$ and Ismail Dogan \\ Thyroidology Unit, Department of Nuclear Medicine, GATA Haydarpasa, Istanbul, Turkey \\ ${ }^{1}$ Department of Nuclear Medicine, Faculty of Medicine, Ege University, Izmir, Turkey \\ ${ }^{2}$ Department of Nuclear Medicine, Sifa Hospital, Izmir, Turkey \\ (Requests for offprints should be addressed to O Turker; Email: otturker@yahoo.com) \\ (O Turker is now at Akademi Medical Centre, Mimar Sinan Mah. 1359 sokak, No. 4A Kyzylkanat Sitesi, Alsancak, Izmir, Turkey)
}

\begin{abstract}
The aim of this study is to investigate the long-term (9 months) effects of variable doses (200/100 $\mu \mathrm{g} /$ day) of L-selenomethionine on autoimmune thyroiditis (AIT) and the parameters affecting the success rate of this therapy. The present study was designed in three steps: (1) 88 female patients with AIT (mean age $=40 \cdot 1 \pm 13 \cdot 3$ years) were randomized into two groups according to their initial serum TSH, thyroid peroxidase antibody (TPOAb) concentrations, and age. All the patients were receiving L-thyroxine to keep serum $\mathrm{TSH} \leq 2 \mathrm{mIU} / \mathrm{l}$. Group S2 $(n=48$, mean TPOAb $=803 \cdot 9 \pm 483 \cdot 8 \mathrm{IU} / \mathrm{ml})$ received $200 \mu \mathrm{g}$ L-selenomethionine per day, orally for 3 months, and group C $(n=40$, mean $\mathrm{TPOAb}=770 \cdot 3 \pm$ $406 \cdot 2 \mathrm{IU} / \mathrm{ml}$ ) received placebo. (2) 40 volunteers of group S2 were randomized into two age- and TPOAb-matched groups. Group S22 $(n=20)$ went on taking L-selenomethionine $200 \mu \mathrm{g}$ /day, while others (group S21) lowered the dose to
\end{abstract}

$100 \mu \mathrm{g} /$ day. (3) 12 patients of group S22 (group S222) went on taking L-selenomethionine $200 \mu \mathrm{g} /$ day, while 12 patients of group S21 (S212) increased the dose to $200 \mu \mathrm{g} /$ day. Serum titers of TPOAb decreased significantly in group S2 $(26 \cdot 2 \%$, $P<0 \cdot 001)$, group S22 $(23 \cdot 7 \%, P<0 \cdot 01)$ and group S212 $(30 \cdot 3 \%, P<0 \cdot 01)$. There were no significant changes in group $\mathrm{C}$ and group S222 $(P>0 \cdot 05)$. TPOAb titers increased significantly in group S21 $(38 \cdot 1 \%, P<0 \cdot 01)$. A significant decrease in thyroglobulin antibody titers was only noted in group S2 $(5 \cdot 2 \%, P<0 \cdot 01)$. L-selenomethionine substitution suppresses serum concentrations of TPOAb in patients with AIT, but suppression requires doses higher than $100 \mu \mathrm{g}$ /day which is sufficient to maximize glutathione peroxidase activities. The suppression rate decreases with time.

Journal of Endocrinology (2006) 190, 151-156

\section{Introduction}

Chronic autoimmune thyroiditis (AIT) is one of the most prevalent autoimmune diseases and affects more than $10 \%$ of females and $2 \%$ of males. Cellular destruction by CD 4 cellmediated autoimmune attacks results in permanent hypothyroidism in more than $90 \%$ of patients (Chistiakov 2005). More than one-third of the patients have other autoimmune diseases such as Sjogren syndrome, myasthenia gravis, vitamin B12 deficiency or celiac disease. AIT is also a well-known risk factor for lymphoma and is being investigated as a potent risk factor for papillary carcinoma.

There is no specific treatment modality to suppress autoimmune destruction and so replacement therapy with L-thyroxine (LT4) has been the only means of palliation. The prophylactic usage of LT4 in euthyroid patients may suppress the serum concentrations of autoantibodies mildly because of a possible decline in antigenic stimulus (due to the rest) of the thyrocytes, not by direct suppression of antibodies (Padberg et al. 2001). Neither corticosteroids nor nonsteroid anti-inflammatory drugs are indicated to inhibit chronic cellular destruction.

The demonstration of a relationship between selenium deficiency and thyroid destruction in myxedematous cretinism and in rat experimental models underlined the importance of selenium (Se) in thyroiditis (Goyens et al. 1987, Contempre et al. 1992, 1993).

After a small pilot study showing a significant decrease in both thyroid peroxidase antibody (TPOAb) and in thyroidstimulating hormone (TSH)-receptor antibody concentrations in patients with AIT (Schmidt et al. 1998), a significant decrease in the mean serum TPOAb levels was also noted with a daily intake of $200 \mu \mathrm{g}(2.53 \mu \mathrm{mol})$ sodium selenite for 3 months $36.4 \%$ in the selenium group versus $12 \%$ in the control group; Gartner et al. 2002). Receiving the same dose of sodium selenite for an additional 6 months resulted in an additional $43 \%$ decrease and cessation of the treatment caused a $57 \%$ increase in the mean TPOAb concentrations (Gartner \& Gasnier 2003). In another study, daily intake of $200 \mu \mathrm{g}$ selenomethionine resulted in a decrease of 46 and $55.5 \%$ 
in serum TPOAb levels after 3 and 6 months treatment, and of 21 and $27 \%$ in the control group respectively. In the pharmacokinetics study, the basal serum concentration of Se $(75 \pm 6 \mu \mathrm{g} / \mathrm{l})$ was within the reference range $(70-125 \mu \mathrm{g} / \mathrm{l})$; it promptly increased at $2 \mathrm{~h}$, peaked at $4 \mathrm{~h}(147 \pm 17 \mu \mathrm{g} / 1$, $P<0 \cdot 0001)$ and it was abundant in serum at $24 \mathrm{~h}$. Thus, selenomethionine is proven to be rapidly absorbed by the gastrointestinal tract (Duntas et al. 2003). No significant change in the mean thyroglobulin antibody (TgAb) levels was noted.

Se is essential for optimal endocrine and immune function and for moderating the inflammatory response. These actions are mediated in most cases through the expression of at least 30 selenoproteins. There are at least six different glutathione peroxidases (GPX); GPX1 is an antioxidant in cell cytosol and may function as a selenium store, GPX3 is an antioxidant in extracellular space and plasma, and GPX4 is a membrane antioxidant and may have a role in apoptosis. Thioredoxin reductases (TR1-3) detoxify peroxides, reduce thioredoxin control of cell growth, and maintain the redox state of transcription factors. Iodothyronine deiodinases type D1 and D2 convert thyroxine (T4) to bioactive 3,5,3'-tri-iodothyronine (T3); type D1 and D3 convert T4 to bio-inactive $3^{\prime}, 3^{\prime}, 5^{\prime}$ reverse T3. Selenoprotein $\mathrm{P}$ is the Se transport protein and is an antioxidant on endothelium. The other types of selenoproteins are defined as $\mathrm{H}, \mathrm{I}, \mathrm{K}, \mathrm{M}, \mathrm{N}, \mathrm{O}, \mathrm{R}, \mathrm{S}, \mathrm{T}$, and V, and most of their functions are still unknown (Beckett \& Arthur 2005).

In Turkey, there is mild/moderate iodine deficiency as well as mild selenium deficiency, as in most European countries (Yanardag \& Orak 2001, Aydin et al. 2002, Cinaz et al. 2004).

The current recommended dietary intake of Se to achieve the maximal activity of GPX in plasma or erythrocytes is between 55 and $75 \mu \mathrm{g} /$ day. Its anticancer effects become prominent with an intake of $200 \mu \mathrm{g} /$ day (Rayman 2000). In another study (also for adults with low serum Se levels), an upper estimated requirement of $90 \mu \mathrm{g} \mathrm{Se} /$ day is calculated as the intake necessary for maximization of plasma GPX activity, as used in the derivation of the US recommended daily allowance (Levander 1997, Duffield et al. 1999). Also, a lower estimated requirement of $39 \mu \mathrm{g} \mathrm{Se} /$ day is the intake necessary to reach two-thirds of maximal GPX activity, as was used in calculating the World Health Organization normative requirement (Levander 1997, Duffield et al. 1999).

Usually authors argue that the replacement of deficient Se stores of GPX plays a major role in the suppression of TPOAb titers in AIT patients. If it is so, it could be achieved by the lower doses of Se too.

This is a critical point, not to optimize the daily dose, but to understand the effect of Se on pathogenesis. However, unfortunately, all of the older studies have been performed with a dose of $200 \mu \mathrm{g} /$ day, which is considerably higher than the limits mentioned above.

Serum Se concentrations do not reflect tissue levels (Kucharzewski et al. 2002, 2003). In fact, intake of a single $200 \mu \mathrm{g}$ dose of Se can produce adequate serum levels in AIT patients, as in normal individuals (Duntas et al. 2003).
Furthermore, in both the studies, serum Se levels of patients were within the normal range $(70-125 \mu \mathrm{g} / \mathrm{l})$ or close to the lower limit, but they responded to Se therapy (Gartner et al. 2002, Duntas et al. 2003). Thus, it requires another question: is there any relationship between the deficiency state of Se and the suppression effect or does Se also have an effect on Sesufficient patients with AIT?

Since there are limited data available to answer these questions, we conducted a blinded, prospective study. Our aims were:

1 To test the effect of $200 \mu \mathrm{g}$ L-selenomethionine/day therapy in a larger group to determine the parameters that may affect the success rates.

2 To observe the dose-response curves by shifting doses $(200-100 \mu \mathrm{g} /$ day) after saturation of tissues with a high dose $(200 \mu \mathrm{g} /$ day) of Se for 3 months, which may exclude any doubt about the Se status of the tissue stores, instead of subjective measurements of the serum Se levels.

3 Finally, to follow the long-term effects of therapy.

\section{Subjects and Methods}

Eighty-eight female patients (mean age $40 \cdot 1 \pm 13 \cdot 3$ years, range 15-77) with known AIT and elevated serum TPOAb $(>100 \mathrm{IU} / \mathrm{ml})$ and/or TgAb $(>188 \mathrm{IU} / \mathrm{ml})$ were included and their informed consent to participate in the study was obtained. The present study was registered and complies with the current laws of the country in which it was performed, inclusive of ethics approval.

Patients were randomized into two groups according to their initial serum TPOAb and TSH concentrations and ages to exclude any difference in serum TPOAb and TSH levels or age. All the patients had been receiving LT4 in a titrated dose to maintain TSH within the lower half of the normal range $(\leq 2 \mathrm{mIU} / \mathrm{l})$. Patients then received either $200 \mu \mathrm{g}$ L-selenomethionine/day (group S2, $n=48$ ), orally or placebo (group C, $n=40$ ) for 3 months (90 days). All the patients were otherwise healthy, but one in the treated group suffered from vitiligo and another one in the same group had discoid lupus. Six in the treated group and four in the control group had serum vitamin B12 levels at the lower limit of the normal range. No patient was receiving corticosteroids, vitamins, trace elements, or antidepressive/antipsychotic drugs.

At the end of the third month, 40 patients from group S2 agreed to go on the study and were randomized into two groups according to their ages and TPOAb concentrations. Group S22 $(n=20)$ went on taking a daily dose of $200 \mu \mathrm{g}$ L-selenomethionine, while the others (group S21, $n=20$ ) lowered the daily dose of Se to $100 \mu \mathrm{g}$. After 3 months, 12 patients of group S22 went on taking a daily dose of $200 \mu \mathrm{g}$ (group S222) and 12 patients of group S21 increased the dose to $200 \mu \mathrm{g}$ again (group S212). Serum TSH, free serum T3 (FT3), free serum T4, (FT4), TPOAb, and TgAb levels were measured at baseline and at the end of each 3-month period during the study. 


\section{Measurements}

Serum concentrations of TPOAb, FT3, and FT4 were measured by RIA and concentrations of $\mathrm{TgAb}$, and TSH were measured by IRMA (Immunotech, Prague, Czech Republic). Normal ranges, analytical sensitivities, intra-assay coefficients of variations $(\mathrm{CV})$, and interassay $\mathrm{CV}$ are:

TSH: $(0 \cdot 17-4 \cdot 05 \mathrm{mIU} / 1) ; 0 \cdot 025 \mathrm{mIU} / 1 ; 3 \% ; 8 \cdot 6 \%$

FT3: $(2 \cdot 5-5 \cdot 8 \mathrm{pM}) ; 0 \cdot 5 \mathrm{pM} ; 5 \cdot 2 \% ; 5 \cdot 5 \%$

FT4: (11.5-23 pM); $0 \cdot 4$ pM; 6.7\%; 6.5\%

TPOAb: (<100 IU/ml); $4 \mathrm{IU} / \mathrm{ml} ; 4 \cdot 26 \% ; 8 \cdot 45 \%$

TgAb: (<188 IU/ml); $5 \mathrm{IU} / \mathrm{ml} ; 5 \cdot 8 \% ; 8 \%$

\section{Statistical analysis}

All the results are presented as means \pm s.D. A multiple linear regression test was performed to investigate the difference between the ages, serum TSH, FT3, and FT4 titers, and the mean values of individual percentage changes in serum TPOAb titers for the 3-month period of the study. Abnormally distributed TPOAb titers were transformed logarithmically to achieve normal distribution values before variance analysis. Variance analysis was performed by twoway ANOVA test to find out the difference in TPOAb titers of Se-treated patients for repeated measurements.

Differences between the groups during the treatment period were analyzed by the Mann-Whitney nonparametric test. The relative changes in TPOAb, TgAb, TSH, FT3, and FT4 concentrations in subgroups were compared using Wilcoxon's matched pairs, signed-ranks test. A $P$ value of $0 \cdot 05$ was considered significant. Instead of simple rates of mean values, percentage changes of titers were presented for every individual measurement.

\section{Results}

A significant decrease was noted in the serum TPOAb levels of the patients by two-way ANOVA compared with the basal values $(P<0 \cdot 001)$. There were significant decrements in the first $(P<0 \cdot 001)$ and the final trimesters $(P<0 \cdot 05)$, but the decrement in the second trimester was not significant because this group also contained increased TPOAb values in group S21 patients. So, in order to analyze subgroups independently, we used Wilcoxon's matched pairs, signed-ranks test.

Mean ages, basal TSH, FT3, FT4, TPOAb, and TgAb titers of group S2 and group C are presented in Table 1. There were no significant differences in ages and initial TSH and TPOAb titers $(P>0 \cdot 05)$.

TSH titers were within the normal range and unchanged in both groups. No correlation was established between the age, TSH, FT3, FT4, and percentage change in TPOAb titers in group S2 $(P>0 \cdot 05)$.

There was a significant decrease in mean TPOAb concentrations in group S2 (from $803 \cdot 9 \pm 483 \cdot 8$ to $572 \cdot 3 \pm 517 \cdot 3 \mathrm{IU} / \mathrm{ml}, 26 \cdot 2 \%$ decrement, $P<0 \cdot 001)$. However, the change was statistically insignificant in the
Table 1 Initial age, serum TSH, FT3, FT4, TPOAb, and TgAb levels (mean \pm s.D.) of group C (receiving LT4 alone) and group S2 (receiving LT4 $+200 \mu \mathrm{g}$ L-selenomethionine/day). There was no significant difference in age, TSH, or TPOAb levels between the groups $(P>0 \cdot 05)$

Age (year)
TSH (mIU/l)
FT3 (pM)
FT4 (pM)
TPOAb $(\mathrm{IU} / \mathrm{ml})$
TgAb $(\mathrm{IU} / \mathrm{ml})$

Age (year) TSH $(\mathrm{mIU} / \mathrm{l})$ TPOAb $(\mathrm{IU} / \mathrm{ml})$
$\operatorname{TgAb}(\mathrm{IU} / \mathrm{ml})$

\begin{tabular}{c} 
Group C \\
\hline $39 \cdot 2 \pm 14 \cdot 4$ \\
$1 \cdot 58 \pm 0 \cdot 50$ \\
$3 \cdot 8 \pm 0 \cdot 5$ \\
$17 \cdot 0 \pm 3 \cdot 6$ \\
$770 \cdot 3 \pm 406 \cdot 2$ \\
$195 \cdot 9 \pm 129 \cdot 9$
\end{tabular}

\section{Group S2}

$$
\begin{gathered}
40 \cdot 8 \pm 12 \cdot 5 \\
1 \cdot 57 \pm 0 \cdot 61 \\
3 \cdot 4 \pm 0 \cdot 7 \\
17 \cdot 1 \pm 3 \cdot 2 \\
803 \cdot 9 \pm 483 \cdot 8 \\
154 \cdot 2 \pm 217 \cdot 3
\end{gathered}
$$

control group (from $770 \cdot 3 \pm 406 \cdot 2$ to $773 \cdot 4 \pm 372 \cdot 9 \mathrm{IU} / \mathrm{ml}$, $P>0 \cdot 05)$.

At the beginning of this study, the mean TgAb concentrations were not identical in both groups, because patients were randomized primarily according to the TPOAb concentrations. The $\mathrm{TgAb}$ concentration in group S2 decreased from $154 \cdot 2 \pm 217 \cdot 3$ to $138 \cdot 8 \pm 205 \cdot 1 \mathrm{IU} / \mathrm{ml}$ (5.2\% decrement, $P<0 \cdot 01)$. In the control group, the change in $\mathrm{TgAb}$ concentration was not significant (from $195 \cdot 9 \pm 129 \cdot 9$ to $188 \cdot 5 \pm 122 \cdot 2 \mathrm{IU} / \mathrm{ml}, P>0 \cdot 05)$. FT3, FT4, as well as TSH values were unchanged in both groups, and all were within the normal range.

The mean values of TPOAb concentrations in group S22 decreased from $649 \cdot 2 \pm 628 \cdot 1$ to $443 \cdot 2 \pm 382 \cdot 5 \mathrm{IU} / \mathrm{ml}$ $(23 \cdot 7 \%$ decrement, $P<0 \cdot 01)$ and mean serum TPOAb concentrations increased from $544 \cdot 3 \pm 380 \cdot 2$ to $694 \cdot 9 \pm$ $427 \cdot 2 \mathrm{IU} / \mathrm{ml}(38 \cdot 1 \%$ increment, $P<0 \cdot 01)$ in group S21. There was no statistically significant difference in serum $\mathrm{TgAb}$ both the S22 and S21 groups.

The mean values of serum TPOAb concentration in group S222 decreased from $451 \cdot 7 \pm 381 \cdot 3$ to $440 \cdot 2 \pm 426 \cdot 7 \mathrm{IU} / \mathrm{ml}$ but the decrement was not significant $(3 \cdot 6 \%$ decrement, $P>$ $0 \cdot 05)$. The mean values of TPOAb concentration in group S212 decreased from $666 \cdot 8 \pm 383 \cdot 1$ to $453 \cdot 2 \pm 233 \cdot 8 \mathrm{IU} / \mathrm{ml}$ $(30 \cdot 3 \%$ decrement, $P<0 \cdot 01)$. There was no statistically significant difference in serum TgAb concentrations in either group (Table 2).

There was no change detected in serum vitamin B12 levels in the patients in group S2 and the control group. Unfortunately, we did not measure the antiparietal cell $\mathrm{Ab}$ titers concomitantly.

The frontal depigmentation in the vitiligo patient decreased by approximately $50 \%$ and the patient with discoid lupus reported a decline in the amount and frequency of lesions after 3 months, although neither of them used any other medication during this period.

One of 48 out of group S2, one of 20 of group S22 and three 12 of group S222 reached normal serum TPOAb range $(<100 \mathrm{IU} / \mathrm{ml})$ and of remained stable.

A 28-year-old female in group S22 received $200 \mu \mathrm{g} \mathrm{Se/day}$ for 6 months. Her TPOAb titer decreased from 1222 to $543.6 \mathrm{IU} / \mathrm{ml}$ in this period, then she became pregnant and preferred not to continue Se therapy. Interestingly, TPOAb 
Table 2 TPOAb levels (mean \pm s.D.) and the mean individual percentage changes in TPOAb levels of the subgroups. Medians and interquartile ranges are presented under mean \pm s.D. values

\begin{tabular}{|c|c|c|c|c|c|}
\hline & $n$ & $\begin{array}{l}\text { TPOAb titer (IU/ml) before } \\
\text { experiment }\end{array}$ & $\begin{array}{l}\text { TPOAb titer }(\mathrm{IU} / \mathrm{ml}) \text { after } 3 \\
\text { months }\end{array}$ & Percentage change & Significance \\
\hline \multicolumn{6}{|l|}{ Group } \\
\hline S2 & 48 & $\begin{array}{l}803 \cdot 9 \pm 483 \cdot 8 \\
648 \cdot 8 ; 390 \cdot 7-116 \cdot 3\end{array}$ & $\begin{array}{l}572 \cdot 3 \pm 517 \cdot 3 \\
340 \cdot 5 ; 215 \cdot 9-631 \cdot 5\end{array}$ & $-26 \cdot 2$ & $P<0 \cdot 001$ \\
\hline S21 & 20 & $\begin{array}{l}544 \cdot 3 \pm 380 \cdot 2 \\
563 \cdot 9 ; 330 \cdot 7-623 \cdot 5\end{array}$ & $\begin{array}{l}694 \cdot 9 \pm 427 \cdot 2 \\
652 \cdot 6 ; 351 \cdot 4-785 \cdot 5\end{array}$ & $38 \cdot 1$ & $P<0 \cdot 01$ \\
\hline S212 & 12 & $\begin{array}{l}666 \cdot 8 \pm 383 \cdot 1 \\
681 \cdot 6 ; 332 \cdot 4-783 \cdot 2\end{array}$ & $\begin{array}{l}453 \cdot 2 \pm 233 \cdot 8 \\
476 ; 228 \cdot 7-648\end{array}$ & $-30 \cdot 3$ & $P<0 \cdot 01$ \\
\hline S222 & 12 & $\begin{array}{l}451 \cdot 7 \pm 381 \cdot 3 \\
236 ; 132 \cdot 7-896 \cdot 6\end{array}$ & $\begin{array}{l}440 \cdot 2 \pm 426 \cdot 7 \\
205 \cdot 7 ; 112 \cdot 3-803 \cdot 6\end{array}$ & $-3 \cdot 6$ & $P>0 \cdot 05$ \\
\hline
\end{tabular}

titers went on declining to $103 \cdot 2 \mathrm{IU} / \mathrm{ml}$ at the end of her pregnancy.

Another 28-year-old patient with a basal TPOAb titer of $1519 \mathrm{IU} / \mathrm{ml}$ also became pregnant at the end of the third month, but she insisted on the therapy $(200 \mu \mathrm{g} \mathrm{Se} / \mathrm{day})$. At the end of 9 months, her serum TPOAb titers reached $192 \cdot 8 \mathrm{IU} / \mathrm{ml}$.

Both pregnancies ended without any problem and, according to routine tests, there was no abnormality reported in the infants.

One patient suffered from gastric discomfort during Se therapy.

\section{Discussion}

Our results confirm that oral administration of $200 \mu \mathrm{g}$ L-selenomethionine/day decreases serum TPOAb titers effectively. There is no relationship detected between the age and the response rate to the treatment. Thus, Se treatment seems to be effective in all age groups, but it must be kept in mind that starting treatment at an early age may save more thyrocytes. Otherwise, it may be ineffective if started later in the late, atrophic phase of the pathology.

There was a sharp decrease in serum TPOAb levels at the beginning of $\mathrm{Se}$ treatment, especially in patients with relatively high serum titers (Figs 1 and 2). However, response rate decreases as the serum concentration of TPOAb decreases, as Gartner et al. (2002) also noted (higher decrement in patients with serum TPOAb titers higher than $1200 \mathrm{IU} / \mathrm{ml}$ ). This data may confirm the 'saturation theory.' However, what is the saturated component of the autoimmune process? Is it really Se store of GPX?

It is clear that $100 \mu \mathrm{g}$ /day is considerably higher than the amount of Se that is required for maximal GPX activity (Levander 1997, Duffield et al. 1999, Rayman 2000). Failure of $100 \mu \mathrm{g}$ L-selenomethionine/day to suppress auto-antibody titers in group S21 patients points to the fact that the therapeutic dose must be higher than the replacement dose of
Se that replenishes deficient GPX stores. For this reason, we tailored the first 3 months of therapy with a high dose of Se. A dramatic increase $(38 \%)$ of mean TPOAb level in group S21 patients and reversal of increment in group S212 patients clearly proved the inefficiency of the low dose.

Lowering of serum TPOAb levels in patients whose GPX stores are saturated suggests that nondeficient AIT patients may respond to $200 \mu \mathrm{g}$ L-selenomethionine/day therapy too. Note that the patients whose serum Se levels were within the normal range $(70-125 \mu \mathrm{g} / \mathrm{l})$ or close to the lower limit responded to Se therapy in both studies (Duntas et al. 2003, Gartner \& Gasnier 2003). Thus, we believe that the suppressive effect of Se is not restricted by deficiency states, Se acts on Se sufficient AIT patients also.

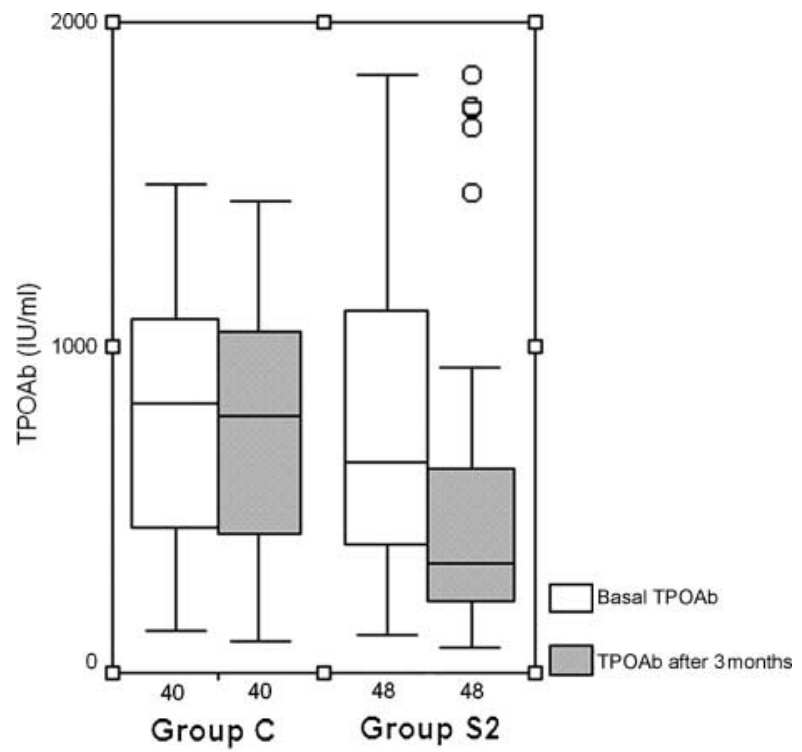

Figure 1 TPOAb concentrations at the beginning of the study and 3 months after treatment with $200 \mathrm{mg}$ L-selenomethionine/day (group S2) or placebo (group C). $P$ values were calculated by Wilcoxon's matched pairs, signed-ranks test. 


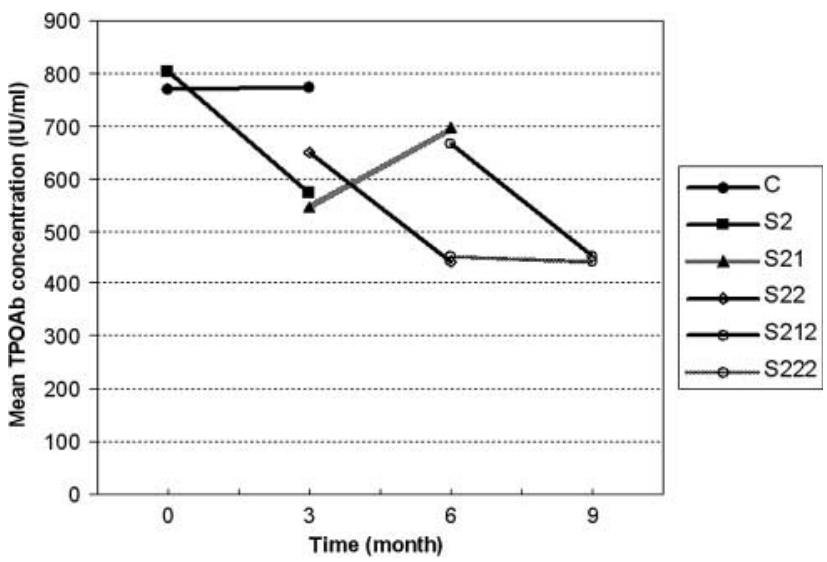

Figure 2 Dose-response curves of subgroups. Note the concordance in decrement rates in groups S2, S22 and S212, who received $200 \mathrm{mg}$ L-selemethionine/day, and the decreased response in group S222.

Rising serum concentrations of TPOAb in group S21 clearly confirms the ineffectiveness of $100 \mathrm{mg}$ L-selemethionine/day.

Transient decrement of mean serum TgAb titer during the first 3 months seems to be unrelated to therapeutic effect of Se. Also, other studies did not find any decrement in the mean TgAb titers (Gartner et al. 2002, Duntas et al. 2003). Many authors attribute this to lesser specificity of $\mathrm{TgAb}$ because $\mathrm{Tg}$ is a circulating antigen and therefore is not necessarily an antigen only expressed during a thyroid-specific autoimmune response. Therefore, $\mathrm{TgAb}$ is less specific for pathogenesis as well as for diagnosis of AIT.

The effectiveness of Se in many other autoimmune diseases like rheumatoid arthritis (Peretz et al. 1992), asthma (Hasselmark et al. 1993, Kadrabova et al. 1996), and lupus erythematosus (Juhlin et al. 1982, Brown 2000) is well documented. It seems that the immunomodulatory effects of this element may be more prominent than the other effects. For selenium supplements augment example, the cellular immune response through increased production of interferon gamma and other cytokines, an early peak T-cell proliferation, and an increase in $\mathrm{T}$ helper cells (Broome et al. 2004). Furthermore, selenoprotein GPX4 may play an important role in apoptosis and TRs affect the control of cell growth.

Unresponsiveness of many AIT patients to Se therapy is interesting. Two hundred micrograms L-selenomethionine/day suppresses autoimmune activity, while lower doses fail. Is it possible that there is any altered Se binding capability of proteins in AIT patients?

We are quite distant from the answers of these questions and we need more data related to molecular biology of selenoproteins. We hope that the results of our study may encourage the initiation of further trials and encourage the thyroidologists to use selenium in the treatment of AIT.

\section{Acknowledgements}

There was no any grant or fellowship supporting the writing of the paper. The authors declare that there is no conflict of interest that would prejudice the impartiality of this scientific work.

\section{References}

Aydin K, Bideci A, Kendirci M, Cinaz P \& Kurtoglu S 2002 Insulin-like growth factor-I and insulin-like growth factor binding protein-3 levels of children living in an iodine- and selenium-deficient endemic goiter area. Biological Trace Element Research 90 25-30.

Beckett GJ \& Arthur JR 2005 Selenium and endocrine systems. Journal of Endocrinology 184 455-465.

Broome CS, Mc Ardle F, Kyle JA, Andrews F, Lowe NM, Hart CA, Arthur JR \& Jackson MJ 2004 An increase in selenium intake improves immune function and poliovirus handling in adults with marginal selenium status. American Journal of Clinical Nutrition 80 154-162.

Brown AC 2000 Lupus erythematosus and nutrition: a review of the literature. Journal of Renal Nutrition 10 170-183.

Chistiakov DA 2005 Immunogenetics of Hashimoto's thyroiditis. Journal of Autoimmune Diseases 21.

Cinaz P, Karakasu DS, Camurdan MO, Bideci A, Ayvali ED \& Yücel C 2004 Goiter prevalence, serum selenium, and urine iodine status in a previously iodine-deficient area in Turkey. Biological Trace Element Research 100 185-193.

Contempre B, Duale NL, Dumont JE, Ngo B, Diplock AT \& Vanderpas J 1992 Effect of selenium supplementation on thyroid hormone metabolism in an iodine and selenium deficient population. Clinical Endocrinology 36 579-583.

Contempre B, Denef JF, Dumont JE \& Many MC 1993 Selenium deficiency aggravates the necrotizing effects of a high iodide dose in iodine deficient rats. Endocrinology 132 1866-1868.

Duffield AJ, Thomson CD, Hill KE \& Williams S 1999 An estimation of selenium requirements for New Zealanders. American Journal of Clinical Nutrition 70 896-903.

Duntas LH, Mantzou E \& Koutras DA 2003 Effects of a six month treatment with selenomethionine in patients with autoimmune thyroiditis. European Journal of Endocrinology 148 389-393.

Gartner R \& Gasnier BC 2003 Selenium in the treatment of autoimmune thyroiditis. Biofactors 19 165-170.

Gartner R, Gasnier BC, Dietrich JW, Krebs B \& Angstwurm MW 2002 Selenium supplementation in patients with autoimmune thyroiditis decreases thyroid peroxidase antibodies concentrations. Journal of Clinical Endocrinology and Metabolism 87 1687-1691. 
Goyens P, Golstein J, Nsombola B, Vis H \& Dumont JE 1987 Selenium deficiency as a possible factor in the pathogenesis of myxoedematous endemic cretinism. Acta Endocrinology 114 497-502.

Hasselmark L, Malmgren R, Zetterstrom O \& Unge G 1993 Selenium supplementation in intrinsic asthma. Allergy 48 30-36.

Juhlin L, Edqvist LE, Ekman LG, Ljunghall K \& Olsson M 1982 Blood glutathione-peroxidase levels in skin diseases: effect of selenium and vitamin E treatment. Acta Dermato Venereologica 62 211-214.

Kadrabova J, Mad'aric A, Kovacikova Z, Podivinsky F, Ginter E \& Gazdik F 1996 Selenium status is decreased in patients with intrinsic asthma. Biological Trace Element Research 52 241-248.

Kucharzewski M, Braziewicz J, Majewska U \& Gozdz S 2002 Concentration of selenium in the whole blood and the thyroid tissue of patients with various thyroid diseases. Biological Trace Element Research 88 25-30.

Kucharzewski M, Braziewicz J, Majewska U \& Gozdz S 2003 Copper, zinc, and selenium in whole blood and thyroid tissue of people with various thyroid diseases. Biological Trace Element Research 93 9-18.

Levander OA 1997 Selenium requirements as discussed in the 1996 joint FAO/IAEA/WHO expert consultation on trace elements in human nutrition. Biomedical and Environmental Sciences 10 214-219.
Padberg S, Heller K, Usadel KH \& Schumm Draeger PM 2001 One-year prophylactic treatment of euthyroid Hashimoto's thyroiditis patients with levothyroxine: is there a benefit? Thyroid 11 249-255.

Peretz A, Neve J, Duchateau J \& Famaey JP 1992 Adjuvant treatment of recent onset rheumatoid arthritis by selenium supplementation: preliminary observations. British Journal of Rheumatology 31 281-282.

Rayman MP 2000 The importance of selenium to human health. Lancet 356 233-241.

Schmidt KJ, Bayer W \& Schweizer T 1998 Selensubstitution-ein therapeutischer Ansatz bei Schilddrusenerkrankungen? VitMinSpur 13 33-39.

Yanardag R \& Orak H 2001 Total selenium concentration in various waters of Turkey. Environmental Technology 22 237-246.
Received in final form 18 March 2006
Accepted 7 April 2006
Made available online as an Accepted Preprint 27 April 2006 